Check for updates

Cite this: RSC Adv., 2017, 7, 39341

Received 8th July 2017

Accepted 4th August 2017

DOI: 10.1039/c7ra07518a

rsc.li/rsc-advances

\section{Study on the kinetics of S(Iv) oxidation in the basic aluminum sulfate wet flue gas desulfurization process}

\author{
Min Chen, (D)*ab Xianhe Deng ${ }^{\mathrm{b}}$ and Feiqiang $\mathrm{He}^{\mathrm{b}}$
}

Through a laboratory-scale bubbling apparatus, the kinetics of S(Iv) oxidation related to the basic aluminum sulfate (BAS) wet flue gas desulfurization (FGD) process were investigated by varying the components of the BAS solution, concentration of S(IV), temperature, air flow and oxygen partial pressure. The experimental findings showed that the oxidation rate of S(IV) slightly increased with $\mathrm{pH}$ as the basicity increased, while increasing the amount of aluminum could weaken the oxidation rate of sulfite. Moreover, the general reaction rate was found to be 0.21 order in S(IV) and first-order in oxygen, respectively. The apparent activation energy was calculated to be $24.5 \mathrm{~kJ} \mathrm{~mol}^{-1}$. Combined with the kinetic model of S(IV) oxidation proposed, we found that the general oxidation rate of S(Iv) in BAS rich solution was controlled by the mass transfer of oxygen accompanied with a rapid chemical reaction, which was verified by the Hatta number (around 1.4). As a result, the intrinsic kinetics were investigated, indicating the reaction orders with respect to S(IV) and oxygen to be 0.42 and 1.0, respectively. The results would be valuable for process optimization or industrial design during the BAS wet FGD process.

\section{Introduction}

With the aim to control sulfur dioxide $\left(\mathrm{SO}_{2}\right)$ emissions into the atmosphere, the treatment of flue gas from the combustion processes of fossil fuels and minerals is indispensable. Until now, various flue gas desulfurization (FGD) processes have been developed for the removal of $\mathrm{SO}_{2}$ from flue gas. Among them, limestone wet scrubbing is the most common commercial process used for the removal of $\mathrm{SO}_{2} \cdot{ }^{1-3}$ But this process is unsatisfactory in practical applications as a result of several major drawbacks, such as the generated wastewater, pipe plugging, poor quality of byproducts, and even secondary pollution. Therefore, a focus on the concept of circular economy, to develop an efficient and economical FGD technology with recycling of the absorbent, is quite desirable for the governance of $\mathrm{SO}_{2}$ pollution.

Compared with the limestone-gypsum method, basic aluminum sulfate (BAS) wet FGD technology has many advantages to remove $\mathrm{SO}_{2}$ from flue gas, such as high desulfurization efficiency, circular utilization of the absorbent, rare fouling, low investment and energy consumption, etc. ${ }^{4-6}$ During the desulfurization process, BAS as the effective absorbent reacts with $\mathrm{SO}_{2}$ from flue gas to form the complex $\mathrm{Al}_{2}\left(\mathrm{SO}_{4}\right)_{3} \cdot \mathrm{Al}_{2}\left(\mathrm{SO}_{3}\right)_{3}$,

${ }^{a}$ Department of Chemistry and Chemical Engineering, Jinggangshan University, Ji'an 343009, People's Republic of China. E-mail: c.m03@mail.scut.edu.cn; Fax: +86-02087111814; Tel: +86-020-87111814

${ }^{b}$ Department of Chemistry and Chemical Engineering, South China University of Technology, Guangzhou 510640, PR China which could reversibly occur decomposition under the condition of heating due to its thermodynamic instability, and that would be further oxidized by oxygen in flue gas as the following reactions: $:^{5,6}$

$$
\mathrm{Al}_{2}\left(\mathrm{SO}_{4}\right)_{3} \cdot \mathrm{Al}_{2} \mathrm{O}_{3}(\mathrm{aq})+3 \mathrm{SO}_{2}(\mathrm{~g}) \underset{\Delta}{\leftrightarrow} \mathrm{Al}_{2}\left(\mathrm{SO}_{4}\right)_{3} \cdot \mathrm{Al}_{2}\left(\mathrm{SO}_{3}\right)_{3}(\mathrm{aq})
$$

$$
\mathrm{Al}_{2}\left(\mathrm{SO}_{4}\right)_{3} \cdot \mathrm{Al}_{2}\left(\mathrm{SO}_{3}\right)_{3}(\mathrm{aq})+\frac{1}{2} \mathrm{O}_{2}(\mathrm{aq}) \rightarrow 2 \mathrm{Al}_{2}\left(\mathrm{SO}_{4}\right)_{3}(\mathrm{aq})
$$

In terms of the desulfurization byproduct, it could be thus divided into two desulfurization processes: BAS-gypsum method and BAS-desorption regeneration method. Through practice, it environmentally indicated that the latter might be the most promising regenerative desulfurization process, whereby $\mathrm{Al}_{2}\left(\mathrm{SO}_{4}\right)_{3} \cdot \mathrm{Al}_{2}\left(\mathrm{SO}_{3}\right)_{3}$ is decomposed by heating or reducing pressure, regenerating BAS with the recovery of pure $\mathrm{SO}_{2}$ used to produce sulfur or sulfuric acid. ${ }^{7}$ In particular, faced with a serious shortage of sulfur sources in China, there are better application prospects for BAS-desorption regeneration process.

For BAS wet FGD process, more investigations have been focused on the $\mathrm{SO}_{2}$ absorption performance. Wen et al. ${ }^{\mathbf{8}}$ researched the influences of components of BAS solution on the desulfurization efficiency. Their results indicated that a large amount of aluminum and high basicity as well $\mathrm{pH}$ were more beneficial for the removal of $\mathrm{SO}_{2}$ from flue gas, while basicity should keep below $40 \%$ to avoid a flocculent precipitation of aluminum hydroxide. In addition, our previous works have 
researched the performance of desulfurization and regeneration regarding to BAS-desorption regeneration method, further proving that it has an excellent feasibility for desulfurization with efficient recycling. ${ }^{6,7}$ However, it should be noted that the oxidation of S(IV) in BAS solution is a key step of desulfurization process. For instance, for BAS-gypsum process, forced oxidation of the S(Iv) in BAS rich solution is desirably needed, while retarding the S(Iv) oxidation is of great importance with respect to BAS-desorption process. Unfortunately, available information of S(Iv) oxidation based on BAS solution is still missing in the field of chemical engineering. Therefore, for better understanding of S(Iv) oxidation in BAS wet FGD process, detailed research is urgently needed.

Except S(Iv) in BAS rich solution, the oxidation kinetics of other kinds of sulfite, and particularly of calcium sulfite, sodium sulfite, magnesium sulfite and ammonium sulfite, have received considerable attentions during the last decades. ${ }^{9-13}$ S(Iv) oxidation was often investigated under homogeneous conditions and heterogeneous conditions. Results obtained in homogeneous conditions are relatively consistent. As reported by Lancia et al., ${ }^{\mathbf{9 , 1 0}}$ they found the reaction to be zero order on oxygen concentration and three-halves on sulfite concentration in range of pH 7.5-9, which is the most appropriate to describe the kinetics of the oxidation reaction in homogeneous conditions. Furthermore, the oxidation mechanism of $\mathrm{S}$ (Iv) in aqueous solution is commonly considered as a chain reaction, which is initiated by the auto-oxidation of catalyst or the action of UV light. ${ }^{\mathbf{1 4 , 1 5}}$ In addition, the published literature indicated that the reaction rate both in homogeneous and heterogeneous is strongly affected by liquid-phase composition ( $\mathrm{S}$ (Iv) concentration, dissolved oxygen, and $\mathrm{pH}$ ), temperature, and presence, even in traces of catalysts $\left(\mathrm{Fe}^{2+}, \mathrm{Cu}^{2+}, \mathrm{Co}^{2+}, \mathrm{Mn}^{2+}\right.$, peracetic acid) and inhibitors (phenols, hydroquinone, alcohols). ${ }^{15,16}$

In recent years, numerous works have reported the kinetics of S(Iv) oxidation under heterogeneous conditions, which is closer to that encountered in practical FGD processes. These studies often experimentally investigate the effects of operation parameters, such as air flow rate, S(Iv) concentration, $\mathrm{pH}$, oxygen partial pressure, and temperature on the oxidation rate of S(Iv) by bubbling air into S(Iv)-loaded solution. For instance, Shaikh et al. ${ }^{17}$ studied the heterogeneous oxidation of aqueous sodium sulfite in the presence of cobalt sulfate as the catalyst, and found that the reaction rate was pseudo-zero-order and first-order with respect to sulfite concentration and catalyst, respectively, while the reaction was first-order with respect to above a critical oxygen partial pressure, second-order in below a critical oxygen partial pressure. As for the sulfite oxidation in magnesium-based wet FGD process, Shen et al. ${ }^{\mathbf{1 1}}$ researched the kinetics parameters of sulfite oxidation using a stirred bubbling reactor, indicating a 0.88 -order in magnesium sulfite, and that diffusion of oxygen was the controlling step of the oxidation process. Jia et al. $^{18}$ also studied the oxidation kinetics of total sulfite in ammonia-based wet FGD process, and found the reaction to be -0.5 order with respect to sulfite at $\mathrm{pH}$ level of 1.4-6.5. Meanwhile, effects of catalysts, such as $\mathrm{Fe}^{2+}, \mathrm{Cu}^{2+}, \mathrm{Co}^{2+}$, and $\mathrm{Mn}^{2+}$ on sulfite oxidation were also widely investigated by many scholars, indicating that the catalysts can strongly affect the reaction rate..$^{190}$

In view of the oxidation kinetics of these sulfites mentioned above, the results obtained for kinetic parameters in various FGD systems were not consistent since the oxidation rate of sulfite is greatly sensitive to experimental conditions. However, for our best knowledge there was no literature reported on the oxidation of S(Iv) related to BAS wet FGD process so far. Hence, to explore the oxidation kinetics of S(Iv) and achieve more data, an independent study is indispensable. In the present work, we not only systematically investigated the kinetics of S(Iv) oxidation in BAS rich solution using a bubbling reactor, but analyzed the general reaction by the combination of mass transfer of oxygen and intrinsic reaction. Furthermore, the kinetic parameters of intrinsic reaction were preliminarily predicted. In all, the results obtained by this study may provide a valuable basis for process design or optimizing operating parameters related to BAS wet FGD process.

\section{Experimental section}

\subsection{Materials}

Both aluminum sulfate $\left[\mathrm{Al}_{2}\left(\mathrm{SO}_{4}\right)_{3} \cdot 18 \mathrm{H}_{2} \mathrm{O}\right]$ and calcium carbonate $\left(\mathrm{CaCO}_{3}\right)$ with the purity of $>99 \%$ were purchased from Tianjin Kermel Chemicals Co., Ltd., China. The $\mathrm{SO}_{2}$ cylinder (purity of $\geq 99 \%$ ) and the $\mathrm{N}_{2}$ cylinder (purity of $\geq 99 \%$ ) were procured from Guangzhou Puyuan Gas Co., Ltd., China. Considering the great sensitive influence of even traces of impurity on the oxidation rate of S(Iv), all the chemicals used in the experiments were of analytical reagent grade.

\subsection{Preparation of $\mathrm{BAS} \mathrm{SO}_{2}$-loaded solution}

Based on the neutralization reaction (reaction (3)), BAS solution was prepared from aluminum sulfate solution, and calcium carbonate was used as the neutralizing reagent. ${ }^{4-6}$

$$
\begin{aligned}
& \mathrm{Al}_{2}\left(\mathrm{SO}_{4}\right)_{3}(\mathrm{aq})+3 x \mathrm{CaCO}_{3}(\mathrm{~s})+6 x \mathrm{H}_{2} \mathrm{O} \rightarrow \\
& (1-x) \mathrm{Al}_{2}\left(\mathrm{SO}_{4}\right)_{3} \cdot x \mathrm{Al}_{2} \mathrm{O}_{3}(\mathrm{aq})+3 x \mathrm{CaSO}_{4} \cdot 2 \mathrm{H}_{2} \mathrm{O}(\mathrm{s})+3 x \mathrm{CO}_{2}(\mathrm{~g})
\end{aligned}
$$

The total amount of aluminum in a BAS solution is represented by $\mathrm{Al}_{2} \mathrm{O}_{3}, \mathrm{~g} \mathrm{~L}^{-1}$; meanwhile, the amount of aluminum expressed as $\mathrm{Al}_{2} \mathrm{O}_{3}$ in formula $(1-x) \mathrm{Al}_{2}\left(\mathrm{SO}_{4}\right)_{3} \cdot x \mathrm{Al}_{2} \mathrm{O}_{3}$ is termed as the "basic amount", $\mathrm{g} \mathrm{L}^{-1}$, meaning that $x$ is "basicity" in reaction (3). ${ }^{4}$

In this work, desired BAS solution was formulated by the method reported in previous literature. ${ }^{6}$ Briefly, an aluminum sulfate solution was neutralized by the addition of calcium carbonate powder, and after $24 \mathrm{~h}$ with stirring the slurry was filtered to obtain the clear solution; meanwhile, the amount of aluminum and basicity in BAS solution were adjusted by adding specified aluminum sulfate and calcium carbonate, respectively.

Unlike other sulfites, such as sodium sulfite, ammonium sulfite, magnesium sulfite, and calcium sulfite, which can be acquired in the form of solid, aluminum sulfite only exists in aqueous solution. Thus, BAS $\mathrm{SO}_{2}$-loaded solution used in the 


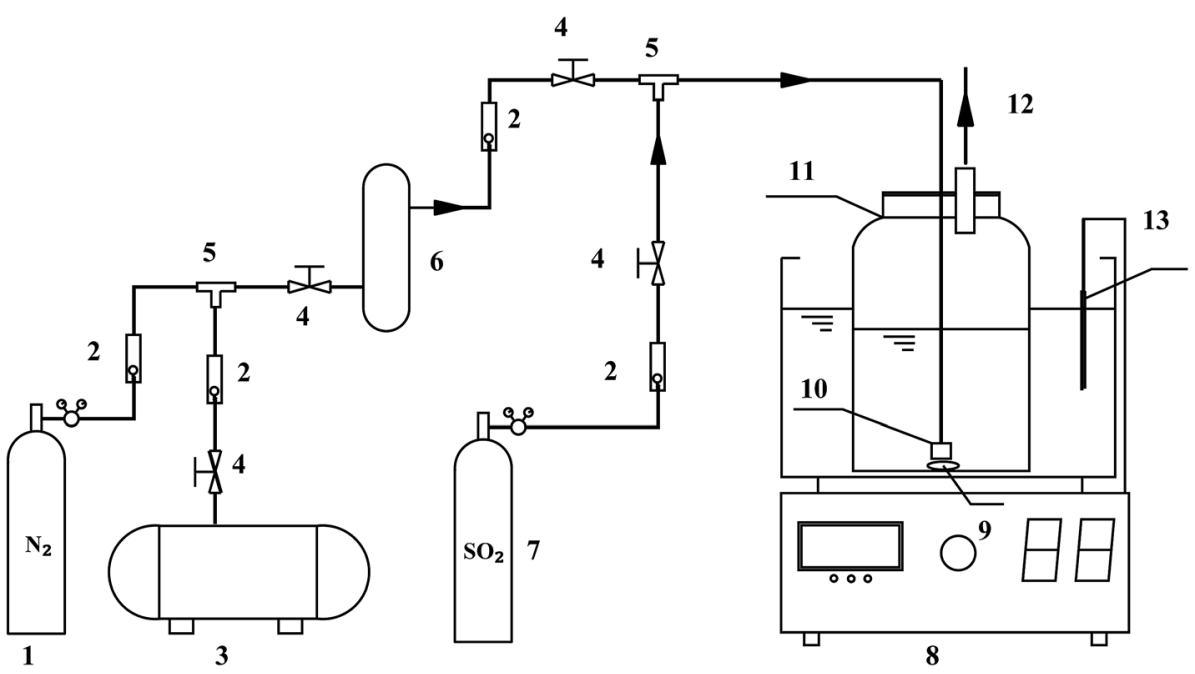

Fig. 1 Experimental apparatus ( $1-\mathrm{N}_{2}$ cylinder; 2 - rotametre; 3 - air compressor; 4 - needle valve; 5 - glass tee; 6 - buffer tank; 7 - SO 2 cylinder; 8 - thermostatic bath with magnetic stirring; 9 - magnetic stirrer; 10 - aeration header; 11 - bubbling reactor; 12 - sampling port; 13 thermometer).

experiments was prepared through bubbling pure $\mathrm{SO}_{2}$ into fresh BAS solution. Water used in all the experimental procedures was deionized water.

\subsection{Experimental method and apparatus}

The oxidation of S(Iv) in BAS rich solution was conducted in a laboratory-scale bubbling reactor. Fig. 1 shows the schematic diagram of the experimental setup used. The bubbling reactor is a glass cylindrical beaker with an inner diameter of $0.070 \mathrm{~m}$. The reaction temperature was controlled by a constant temperature water bath within small variation of $\pm 0.1 \mathrm{~K}$. Before performing the experiments, $400 \mathrm{~mL}$ of fresh BAS solution prepared was added into the bubbling reactor which was installed in a constant-temperature bath with stirrer. Until temperature of the solution reach the desired value, pure $\mathrm{SO}_{2}$ would be introduced into the solution. The fixed S(Iv) concentration was regulated by $\mathrm{pH}$ meter. A hydrochloric acid and sodium hydroxide was used to adjust the $\mathrm{pH}$ value. After that, the pure nitrogen and air mixed in a specified ratio by flow adjustment was injected into the solution in a steady manner. Subsequently the reaction started and the time was recorded at the same time. Varying operating parameters, the experimental procedure above was conducted and repeated. A trace amount of sample was taken out at intervals in order to measure the concentration of S(Iv) and sulfate, respectively. The concentration of S(Iv) was determined using standard iodometric titration method. And the concentration of sulfate in solution was measured by means of ion chromatography. The specific oxidation rate of $\mathrm{S}(\mathrm{Iv})$ was calculated by the following equation: ${ }^{11}$

$$
r=\mathrm{d}_{\mathrm{SO}_{4}}{ }^{2-} / \mathrm{d} t=-\mathrm{d} C_{\mathrm{S}(\mathrm{Iv})} / \mathrm{d} t
$$

Every experiment was repeated at least three times. According to the data from a single series from experiments, the oxidation rate of S(Iv) shown in the figures can be evaluated by the method of initial rates. ${ }^{18,21}$ The relative deviations during all the experiments are less than $5 \%$ for $\mathrm{S}(\mathrm{Iv})$ concentration, $2 \%$ for sulfate concentration, $2 \%$ for $\mathrm{pH}$ value, $4 \%$ for air flow, and $2 \%$ for temperature.

\section{Results and discussion}

\subsection{Effect of component of BAS solution}

The component of BAS solution plays a very important role during BAS wet FGD process. And it can be defined by both the amount of aluminum and the basicity, of which the two terms have been represented in previous literature. ${ }^{6}$ Thus, a series of experiments were performed to comprehend the effect of the component of BAS solution on the oxidation rate of S(Iv). As seen in Fig. 2, it shows that the amount of aluminum have significant effect on the oxidation rate of sulfite. For example, when the amount of aluminum increased from $15-30 \mathrm{~g} \mathrm{~L}^{-1}$, the

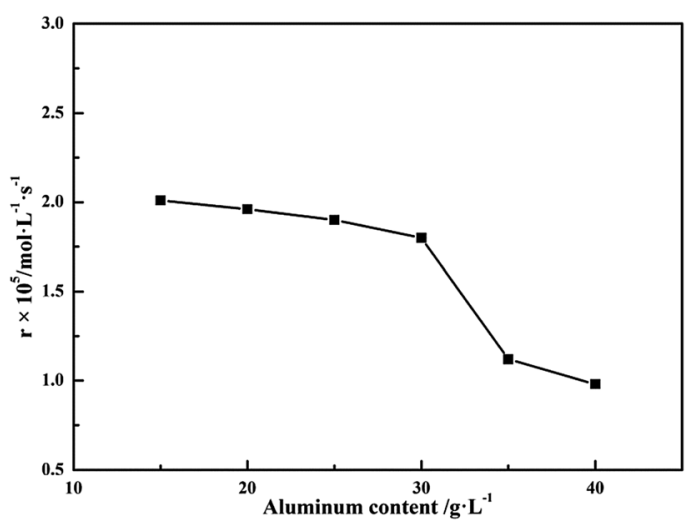

Fig. 2 Effect of amount of aluminum on the oxidation rate (basicity, 25\%; $C_{\mathrm{S}(\mathrm{v})}=0.01 \mathrm{~mol} \mathrm{~L}^{-1} ; T=303 \mathrm{~K} ; \mathrm{Q}=84 \mathrm{~L} \mathrm{~h}^{-1} ; \mathrm{pH}=3.40$; oxygen partial pressure, $0.21 \mathrm{~atm})$. 
oxidation rate had a slight reduction in range of 2.06-1.80 $\times$ $10^{-5} \mathrm{~mol}\left(\mathrm{~L}^{-1} \mathrm{~s}^{-1}\right)$; nevertheless, the oxidation rate of $\mathrm{S}$ (Iv) dramatically decreased from 1.80-0.98 $\times 10^{-5} \mathrm{~mol}\left(\mathrm{~L}^{-1} \mathrm{~s}^{-1}\right)$ with a rise of the amount of aluminum in range of $30-40 \mathrm{~g} \mathrm{~L}^{-1}$, indicating that excessive amount of aluminum could seriously hamper the oxidation of S(Iv). One reason may be that excess aluminum sulfate can cause the reduction of liquid-phase mass transfer coefficient owing to the changes of the physical properties of the solution, such as ionic strength, density, viscosity, and diffusion coefficients. ${ }^{22,23}$ Another reason may be due to the decrease in the solubility of oxygen dissolved in BAS rich solution. ${ }^{24}$ Therefore, the amount of aluminum should be below $30 \mathrm{~g} \mathrm{~L}^{-1}$ for larger oxidation rate of S(Iv) during BAS-gypsum desulfurization process.

Additionally, it should be noted that the basicity of BAS solution with specific amount of aluminum is closely related to $\mathrm{pH}$ value of the solution. Fig. 3 shows the relation between the basicity and the $\mathrm{pH}$ with $0.01 \mathrm{~mol} \mathrm{~L}^{-1} \mathrm{~S}$ (Iv) concentration. As seen in Fig. 3, it is obvious that the oxidation rate of $\mathrm{S}$ (IV) has a little increase with the rise of the basicity from $5-30 \%$, which also improves the $\mathrm{pH}$ value in range from 2.89-3.43. Furthermore, after linear fitting the experimental data, Fig. 4 show that the oxidation rate of $\mathrm{S}(\mathrm{IV})$ is proportional to $10^{0.127} \mathrm{pH}$ with a correlation coefficient of 0.97 , meaning that increasing the $\mathrm{pH}$ will slightly enhance the oxidation rate of sulfite. In comparison with the data reported in the literature, this tendency is somewhat similar to that reported by Gürkan et al. on ammonium sulfite and Bengtsson et al. on sodium sulfite. ${ }^{12,25}$ However, Jia et al. and Zhou et al. reported that the oxidation rate of ammonium sulfite decreases as the $\mathrm{pH}$ value ranges from 4.56.5 , while Gürkan et al. found that the oxidation rate of S(Iv) increases with $\mathrm{pH}$ range of 7-8.12,18,26 These results mentioned above for the effect of $\mathrm{pH}$ on the oxidation rate of S(Iv) seem to be contradictory. In general, under different $\mathrm{pH}$ values, the interaction of various impact factors may make the changes of oxidation reaction. The main reason that the increase of $\mathrm{pH}$ improved the oxidation rate of S(Iv) in BAS rich solution could be explained as follows: since the ratio of bisulfate concentration to S(Iv) concentration was almost stable with a high value as

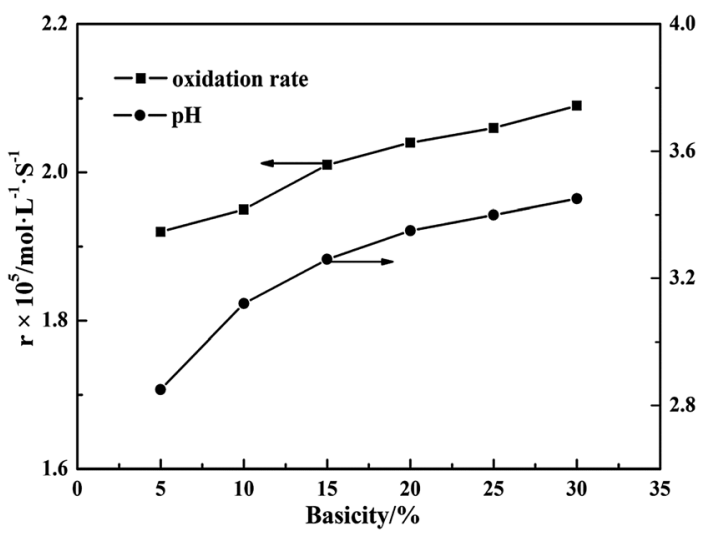

Fig. 3 Effect of basicity on the oxidation rate (amount of aluminum, $15 \mathrm{~g} \mathrm{~L}^{-1} ; C_{\mathrm{S}(\mathrm{iv})}=0.01 \mathrm{~mol} \mathrm{~L}^{-1} ; T=303 \mathrm{~K} ; \mathrm{Q}=84 \mathrm{~L} \mathrm{~h}^{-1}$; oxygen partial pressure, $0.21 \mathrm{~atm})$.

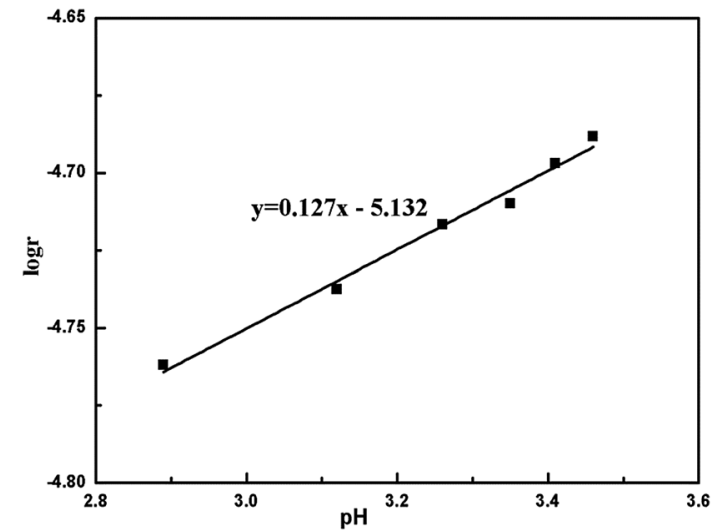

Fig. 4 Relationship between $\mathrm{pH}$ and oxidation rate (amount of aluminum, $15 \mathrm{~g} \mathrm{~L}^{-1} ; C_{\mathrm{S}(\mathrm{iv})}=0.01 \mathrm{~mol} \mathrm{~L}^{-1} ; T=303 \mathrm{~K} ; \mathrm{Q}=84 \mathrm{~L} \mathrm{~h}^{-1}$; oxygen partial pressure, $0.21 \mathrm{~atm})$.

the $\mathrm{pH}$ varied from $2.89-3.43$, the influence of oxygen on the $\mathrm{S}$ (Iv) oxidation would be dramatically weakened with a decrease of $\mathrm{pH}$, leading to a lower oxidation rate of sulfite. ${ }^{\mathbf{1 1 , 2 7}}$ In present work, the $\mathrm{pH}$ value was adjusted by the basicity, which is lower than others reported in literature. ${ }^{\mathbf{1 1 2 1 2 , 1 8}}$ Thus, the independent investigation is meaningful for grasping the information of the kinetics of the $\mathrm{S}(\mathrm{Iv})$ oxidation affected by $\mathrm{pH}$.

\subsection{Effect of S(Iv) concentration}

A number of experiments were carried out to demonstrate the effect of S(Iv) concentration on the oxidation rate of S(Iv) with $\mathrm{pH}$ $=3.40$. Fig. 5 clearly shows that the oxidation rate of S(Iv) increases with the S(Iv) concentration. Furthermore, the oxidation rate of $\mathrm{S}$ (Iv) can be found to be 0.21 order with respect to $\mathrm{S}$ (Iv) and with a correlation coefficient of 0.99 , as shown in subgraph in Fig. 4. Zhou et al. $^{26}$ found that the oxidation rate of ammonium sulfite is 0.20 order dependence from sulfite concentration below a critical concentration, above which the order turns to -1.0 . Neelakantan et $a .^{28}$ reported that the reaction is 2.0 order with respect to ammonium sulfite. Further,

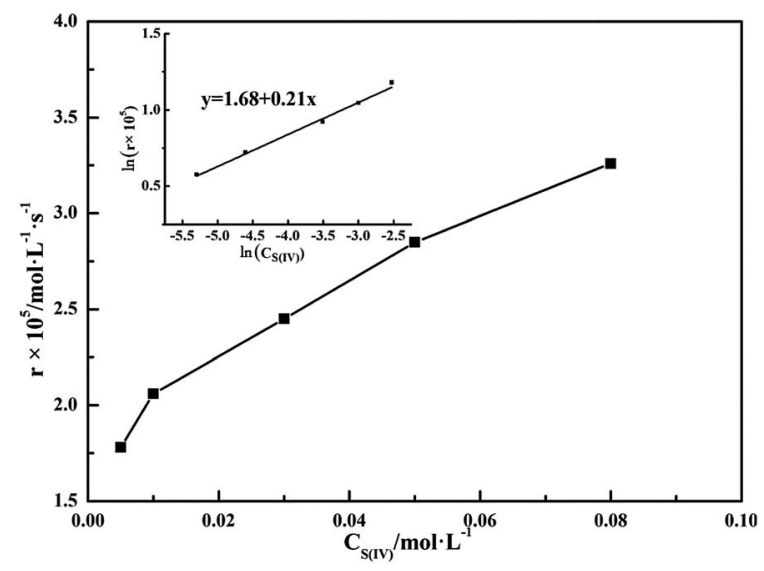

Fig. 5 Effect of S(IV) concentration on the oxidation rate (amount of aluminum, $15 \mathrm{~g} \mathrm{~L}^{-1}$; basicity, $25 \% ; T=303 \mathrm{~K} ; \mathrm{Q}=84 \mathrm{~L} \mathrm{~h}^{-1} ; \mathrm{pH}=3.40$; oxygen partial pressure, $0.21 \mathrm{~atm})$. 


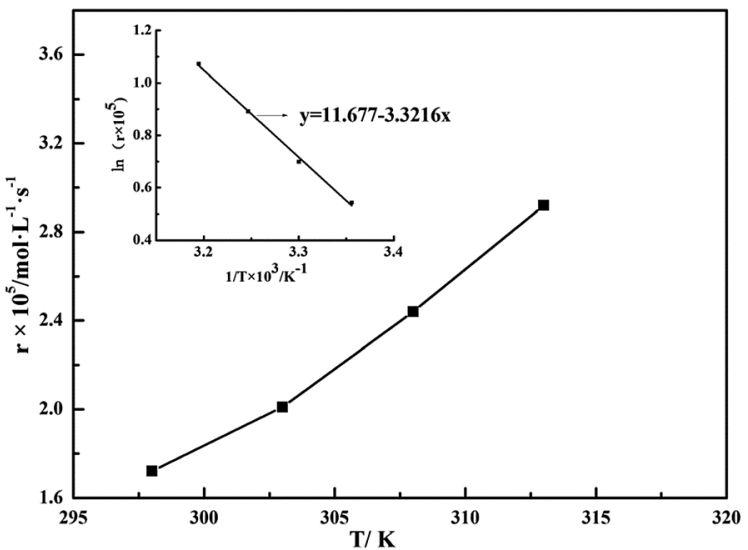

Fig. 6 Effect of temperature on the oxidation rate (amount of aluminum, $15 \mathrm{~g} \mathrm{~L}^{-1}$; basicity, $25 \% ; C_{\mathrm{S}(\mathrm{v})}=0.01 \mathrm{~mol} \mathrm{~L}^{-1} ; \mathrm{Q}=84 \mathrm{~L} \mathrm{~h}^{-1}$; $\mathrm{pH}=3.40$; oxygen partial pressure, $0.21 \mathrm{~atm}$ ).

Shen $e t$ al. ${ }^{11}$ found the reaction to be 0.88 order with respect to magnesium sulfite. Li et $a l .^{19}$ found the reaction to be zero order with respect to magnesium sulfite in presence of catalyst. However, Jia et al. ${ }^{18}$ reported the reaction to be -0.5 order with respect to ammonium sulfite. In a whole, these mentionedabove literatures gave inconsistent results, likely resulting from the different characteristics of sulfites and the experimental conditions, such as ranges of $\mathrm{S}(\mathrm{Iv})$ concentration, $\mathrm{pH}$, reactors and ionic strength.

\subsection{Effect of temperature}

Fig. 6 shows that the oxidation rate of S(Iv) increases slowly with the rise of temperature. This same tendency was also shown in the published literature. ${ }^{11,18,19}$ According to the Arrhenius formula

$$
\ln k_{\text {in }}=\ln k_{0}-\frac{E_{\mathrm{a}}}{R} \frac{1}{T},
$$

where $k_{0}$ is the frequency factor; $E_{\mathrm{a}}$ is the apparent activation

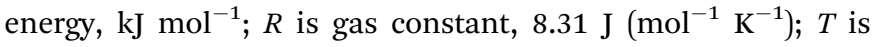
temperature, $\mathrm{K}$; and the reaction rate constant $k_{\text {in }}$ between $\mathrm{SO}_{3}{ }^{2-}$ and $\mathrm{O}_{2}$ dissolved in aqueous solution which quantifies the speed of a chemical reaction increases as the temperature increases, causing the rise of the oxidation rate. As shown in sub-graph in Fig. 6, the temperature dependency is in accordance with the Arrhenius formula (eqn (5)), indicating that the apparent activation energy for the overall oxidation can be calculated to be $24.5 \mathrm{~kJ} \mathrm{~mol}^{-1}$, which is close to that reported by Jia et al..$^{18}$ However, this value is higher than the activation energy previously proposed by Shen $e t$ al. and Gürkan et al. ${ }^{11,12}$ The main reason for different value of the apparent activation energy obtained may be due to the influence of some factors, such as catalysts, inhibitors, and different characters of S(Iv)loaded solution.

\subsection{Effect of air flow}

The effect of air flow on the oxidation rate of S(Iv) is shown in Fig. 7. It is obvious that the air flow has significant influence on

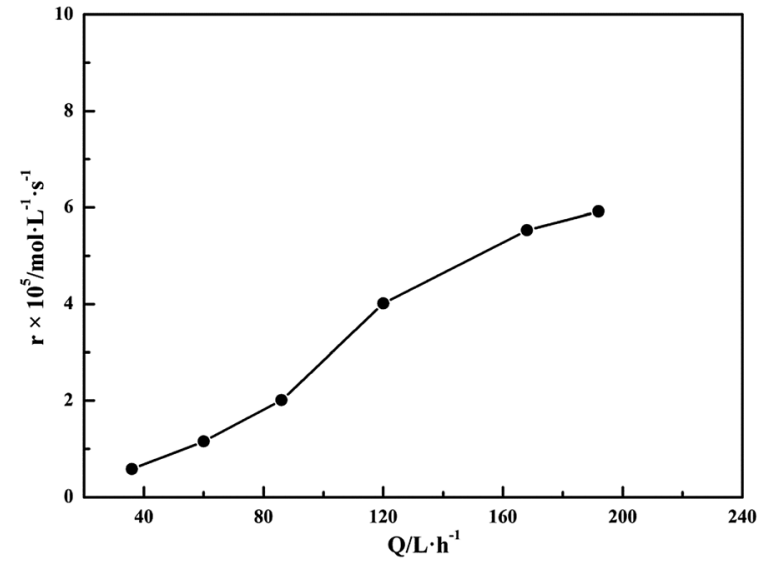

Fig. 7 Effect of air flow on the oxidation rate (amount of aluminum, $15 \mathrm{~g} \mathrm{~L}^{-1}$; basicity, 25\%; $C_{\mathrm{S}(\mathrm{v})}=0.01 \mathrm{~mol} \mathrm{~L}^{-1} ; T=303 \mathrm{~K} ; \mathrm{pH}=3.40$; oxygen partial pressure, $0.21 \mathrm{~atm})$.

the oxidation rate of sulfite. The oxidation rate of S(Iv) dramatically increased as the air flow increased to $120 \mathrm{~L} \mathrm{~h}^{-1}$, while above which it rose slowly. This tendency is in agreement with the previous reports. ${ }^{12,18}$ The reason can be explained that the gas-liquid contact area will increase with the rise of air flow, causing larger reaction rate between $\mathrm{S}(\mathrm{Iv})$ and oxygen based on the two-film theory. On the other hand, when the air flow was below $120 \mathrm{~L} \mathrm{~h}^{-1}$, the bubbled air could disperse uniformly, and had a positive stirring influence on the reaction solution, strengthening the gas-liquid mass transfer; however, with the air flow up $120 \mathrm{~L} \mathrm{~h}^{-1}$, some air froth collided and agglomerated, causing little change of gas-liquid contact area and a turbulent bubbling status. ${ }^{18,29}$

\subsection{Effect of oxygen partial pressure}

Fig. 8 shows that the oxygen partial pressure has significant effect on the oxidation rate of sulfite, indicating that the

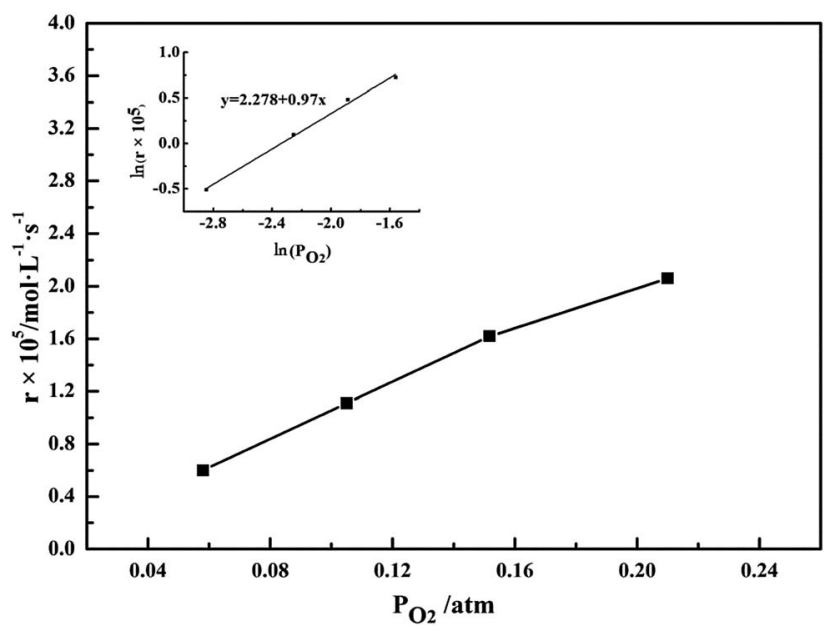

Fig. 8 Effect of oxygen partial pressure on the oxidation rate (amount of aluminum, $15 \mathrm{~g} \mathrm{~L}^{-1}$; basicity, $25 \% ; C_{S(\mathrm{v})}=0.01 \mathrm{~mol} \mathrm{~L}^{-1} ; \mathrm{pH}=3.40 ; T$ $=303 \mathrm{~K} ; \mathrm{Q}=84 \mathrm{~L} \mathrm{~h}^{-1}$ ). 
oxidation rate of S(Iv) almost increases linearly with the oxygen partial pressure raised from 0.05-0.21 atm. Furthermore, we can find the reaction to be first order with respect to oxygen partial pressure and with a correlation coefficient of 0.99 , as shown in sub-graph in Fig. 7. This result can gain much support from the reports of Zhou et al., Ahmad et al. and Neelakantan et al. ${ }^{26,28,30}$

\section{Kinetic model}

According to the oxidation process of S(Iv) presented in the literature, ${ }^{11,19}$ the investigation of S(Iv) oxidation based on BAS solution can be divided into two steps, including an intrinsic chemical reaction between S(Iv) and dissolved oxygen in BAS rich solution and absorption of oxygen from gas bubbles into the solution. Hence, the overall oxidation rate will be determined by the two processes above.

\subsection{Intrinsic reaction}

The intrinsic chemical reaction for sulfite oxidation in aqueous solution is widely recognized as a chain reaction, which can be initiated by catalytic species or UV light. ${ }^{\mathbf{3} 10}$ However, results for the reaction orders reported in public literature are yet inconsistent. Generally, the intrinsic reaction rate $r_{\mathrm{A}}$ can be expressed as the following equation: ${ }^{10,19}$

$$
r_{\mathrm{A}}=k_{\mathrm{in}} C_{\mathrm{S}(\mathrm{Iv})}^{m} C_{\mathrm{O}_{2}}^{n}
$$

where $m$ and $n$ represent the reaction orders of S(Iv) and dissolved oxygen, respectively; $C_{\mathrm{S}(\mathrm{Iv})}$ and $C_{\mathrm{O}_{2}}$ are the concentrations of $\mathrm{S}(\mathrm{IV})$ and dissolved oxygen in aqueous solution, respectively; and $k_{\text {in }}$ is the rate constant of the intrinsic non-catalytic chemical reaction, which is closely related to the temperature and properties of $\mathrm{S}$ (Iv)-loaded solution, such as $\mathrm{pH}$ and components of solution.

\subsection{Absorption of oxygen}

Considering the solubility of oxygen dissolved in aqueous solution, the mass transfer of oxygen into solution was considered to be controlled by liquid-phase resistance. Since the diffusion of oxygen accompanied with chemical reaction, the absorption rate of oxygen $r_{\mathrm{B}}$ could be given as follows: ${ }^{19}$

$$
\begin{gathered}
r_{\mathrm{B}}=k_{\mathrm{L}} a E\left(C_{\mathrm{O}_{2} \mathrm{i}}-C_{\mathrm{O}_{2}}\right) \\
E=(1+M)^{0.5}
\end{gathered}
$$

where $k_{\mathrm{L}}$ is the liquid mass transfer coefficient $\left(\mathrm{m} \mathrm{s}^{-1}\right)$; $a$ denotes the gas-liquid interface area per unit volume of liquid $\left(\mathrm{m}^{2} \mathrm{~m}^{-3}\right) ; E$ represents the enhancement factor relative to physical absorption; $C_{\mathrm{O}_{2} \mathrm{i}}$ is the concentration of oxygen in gasliquid interface $\left(\mathrm{mol} \mathrm{L}^{-1}\right)$; which is directly proportional to the partial pressure of oxygen in gas phase based on the Henry's Law; and $\sqrt{M}$ is the Hatta number used to judge whether a chemical reaction is rapid reaction or not, and it can be expressed by ${ }^{11}$

$$
\sqrt{M}=\frac{\left[\frac{2}{n+1} D_{\mathrm{O}_{2}} k_{\mathrm{in}} C_{\mathrm{S}(\mathrm{IV})}{ }^{m} C_{\mathrm{O}_{2}{ }^{n+1}}\right]^{1 / 2}}{k_{\mathrm{L}}}
$$

According to the previous results published by others, ${ }^{11,18,19}$ the $\mathrm{S}$ (Iv) oxidation in BAS rich solution could be assumed to be a rapid reaction, indicating that $C_{\mathrm{O}_{2}}$ could be neglected with respect to $C_{\mathrm{O}_{2}}$. Thus, the absorption rate of oxygen $r_{\mathrm{B}}$ can be simplified as

$$
r_{\mathrm{B}}=a\left[\frac{2}{n+1} D_{\mathrm{O}_{2}} k_{\mathrm{in}} C_{\mathrm{S}(\mathrm{IV})}{ }^{m} C_{\mathrm{O}_{2} \mathrm{i}}{ }^{n+1}\right]^{1 / 2}
$$

\subsection{General oxidation}

Similar to the oxidation process of magnesium sulfite reported in the literature, ${ }^{\mathbf{1 1}, 19}$ the overall oxidation rate of S(Iv) in BAS rich solution $r$ will be controlled by the slowest step, namely if the intrinsic reaction is the controlling step, there is $r=r_{\mathrm{A}}$, otherwise $r=2 r_{\mathrm{B}}$, which is also written as eqn (11).

$$
r=\min \left(r_{\mathrm{A}}, 2 r_{\mathrm{B}}\right)
$$

Supposing that the general oxidation rate was controlled by the intrinsic reaction rate, the flow rate would have little influence on the overall reaction rate, which is in contradiction to the experimental results in Fig. 7. On the other hand, the temperature should have considerable effect on the overall reaction rate as a result of the controlling step of intrinsic reaction. Nevertheless, the apparent activity energy was calculated to be $24.5 \mathrm{~kJ} \mathrm{~mol}^{-1}$, indicating that temperature has no significant effect on the general reaction rate. In addition, the published results for macroscopic oxidation of others sulfites with catalysis or without also show that the intrinsic reaction is not the controlling step. ${ }^{18,19}$ Thus, it can infer that the general oxidation process is controlled by the absorption of oxygen with a rapid chemical reaction.

In order to further test the validity of the proposed fastreaction regime assumption, it is necessary to check the value of $\sqrt{M}$, and according to eqn (11), we can obtained the following equation: ${ }^{17,19}$

$$
\sqrt{M}=\frac{r}{2 k_{\mathrm{L}} a C_{\mathrm{O}_{2} \mathrm{i}}}
$$

The liquid-phase mass transfer coefficient $k_{\mathrm{L}}$ can be given by $^{6,31}$

$$
k_{\mathrm{L}}=0.5 \mathrm{~g} D_{\mathrm{O}_{2}}{ }^{1 / 2} \rho_{\mathrm{L}}{ }^{3 / 8} \sigma_{\mathrm{L}}{ }^{-3 / 8} d_{V S}{ }^{1 / 2}
$$

with

$$
d_{V S}=26 D_{\mathrm{R}}\left(\frac{g D_{\mathrm{R}}^{2} \rho_{\mathrm{L}}}{\sigma_{\mathrm{L}}}\right)^{-0.5}\left(\frac{g D_{\mathrm{R}}^{3} \rho_{\mathrm{L}}^{2}}{\mu_{\mathrm{L}}^{2}}\right)^{-0.12}\left(\frac{u_{\mathrm{G}}}{\sqrt{g D_{\mathrm{R}}}}\right)^{-0.12}
$$

where $d_{V S}$ is the volume-surface mean bubble diameter, $m ; D_{\mathrm{O}_{2}}$ is the diffusion coefficients of $\mathrm{O}_{2}$ in water, $\mathrm{m}^{2} \mathrm{~s}^{-1} ; D_{\mathrm{R}}$ is the 
diameter of bubbling column, $m, \rho_{\mathrm{L}}$ is the density of solution, $\mathrm{kg} \mathrm{m}{ }^{-3} ; \sigma_{\mathrm{L}}$ is the surface tension of solution, $\mathrm{N} \mathrm{m}^{-1} ; \mu_{\mathrm{L}}$ is the viscosity of solution, pa $\mathrm{s} ; u_{\mathrm{G}}$ is the superficial velocity, $\mathrm{m} \mathrm{s}^{-1}$; and $g$ is gravitational constant, $\mathrm{m} \mathrm{s}^{-2}$.

The specific gas-liquid interfacial area $a$ can be written by ${ }^{31,32}$

$$
a=\frac{6 \varepsilon_{\mathrm{G}}}{\mathrm{d}_{V S}}
$$

where $\varepsilon_{\mathrm{G}}$ is the gas holdup in bubble column rector, which can be expressed as $^{31,33}$

$$
\frac{\varepsilon_{\mathrm{G}}}{\left(1-\varepsilon_{\mathrm{G}}\right)^{4}}=0.27 \times\left(\frac{u_{\mathrm{G}} \mu_{\mathrm{L}}}{\sigma_{\mathrm{L}}}\right)\left(\frac{\rho_{\mathrm{L}} \sigma_{\mathrm{L}}^{3}}{\mathrm{~g} \mu_{\mathrm{L}}{ }^{3}}\right)^{7 / 24}
$$

For the oxidation process of S(Iv) in present study, the kinetic characteristics $\left(k_{\mathrm{L}}\right.$ and $a$ ) can be calculated by the formulas mentioned above. And Table 1 shows the values of model parameters. ${ }^{6,11}$ At $303 \mathrm{~K}, 15 \mathrm{~g} \mathrm{~L}^{-1}$ amount of aluminum, 25\% basicity, and $0.01 \mathrm{~mol} \mathrm{~L}^{-1} \mathrm{~S}$ (Iv) concentration, the liquid-phase mass transfer coefficient $k_{\mathrm{L}}$ is estimated to be approximately 4.8 $\mathrm{m} \mathrm{s}^{-1}$ by eqn (13), and the interfacial area $a$ ranges from $50-260$ $\mathrm{m}^{2} \mathrm{~m}^{-3}$ in the experiments by eqn (15). The equilibrium concentration of oxygen at the interface $C_{\mathrm{O}_{2} \mathrm{i}}$ is calculated to be $(0.21 \mathrm{~atm}) H=1.22 \times 10^{-4} \mathrm{~mol} \mathrm{~L}^{-1}$ with the solubility of oxygen $H=5.8 \times 10^{-4} \mathrm{~mol}\left(\mathrm{~L}^{-1} \mathrm{~atm}^{-1}\right)$ at $303 \mathrm{~K} .{ }^{11,19}$ Thus the Hatta number $\sqrt{M}$ was estimated to be about 1.4, which is higher than 1.0, and the result is close to that reported by Shen et al. ${ }^{\mathbf{1 1}}$ As a result, the reaction can be fully considered as a fast chemical reaction. ${ }^{3}$

According to the analysis above, we determined that the general oxidation process was controlled by the mass transfer of oxygen accompanied with rapid chemical absorption, which can be expressed by eqn (17).

$$
r=2 a\left[\frac{2}{n+1} D_{\mathrm{O}_{2}} k_{\text {in }} C_{\mathrm{S}_{(\mathrm{Iv})}}{ }^{m} C_{\mathrm{O}_{2} \mathrm{i}}{ }^{n+1}\right]^{1 / 2}
$$

Consequently, based on the macroscopic oxidation results shown in the present work, we attempted to acquire the intrinsic reaction orders. As shown in Fig. 4, the order of the general oxidation rate is 0.21 with respect to $\mathrm{S}$ (Iv) concentration, indicating that the order of the intrinsic reaction with respect to sulfite, namely $m$ is 0.42 . Furthermore, the reaction order with respect to oxygen partial pressure in the intrinsic reaction, namely $n$ is convinced to be 1 because the general oxidation rate is first-order dependence on oxygen partial pressure as mentioned in Section 3.5.

Table 1 Values of model parameters at $303 \mathrm{~K}$

\begin{tabular}{lll}
\hline Parameter & Value & Unit \\
\hline$D_{\mathrm{O}_{2}}$ & $2.6 \times 10^{-9}$ & $\mathrm{~m}^{2} \mathrm{~s}^{-1}$ \\
$\rho_{\mathrm{L}}$ & 1050 & $\mathrm{~kg} \mathrm{~m}^{-3}$ \\
$\sigma_{\mathrm{L}}$ & $7.2 \times 10^{-2}$ & $\mathrm{~N} \mathrm{~m}^{-1}$ \\
$\mu_{\mathrm{L}}$ & $1.012 \times 10^{-3}$ & $\mathrm{~N}\left(\mathrm{~m}^{-2} \mathrm{~s}^{-1}\right)$ \\
$D_{\mathrm{R}}$ & $7 \times 10^{-2}$ & $\mathrm{~m}$
\end{tabular}

\section{Conclusions}

Compared with the widely studied oxidation of other kinds of sulfite in the literature of chemical engineering, the S(Iv) oxidation in BAS-based wet FGD process has not been fully addressed, which is great important for dealing well with the desulfurization by-product. In this paper, using the laboratoryscale bubbling apparatus, the oxidation process of S(Iv) related to BAS wet FGD process was systematically investigated under different operating conditions including amount of aluminum, basicity, air flow, S(Iv) concentration, oxygen partial pressure and temperature. The experimental results indicate that the amount of aluminum with $30 \mathrm{~g} \mathrm{~L}^{-1}$ above had considerable influence on the oxidation rate of $\mathrm{S}(\mathrm{Iv})$. When $\mathrm{pH}$ value increased from 2.65 to 3.45 with a rise of the basicity from 5$30 \%$, the oxidation rate of S(Iv) increased slightly from 1.92-2.09 $\times 10^{-5} \mathrm{~mol}\left(\mathrm{~L}^{-1} \mathrm{~s}^{-1}\right)$. Moreover, the oxidation rate of $\mathrm{S}$ (Iv) can be considerably accelerated by increasing the air flow or oxygen partial pressure, while the $\mathrm{S}$ (Iv) concentration and temperature will slightly affect the oxidation rate of sulfite. The apparent activation energy for the overall oxidation reaction was calculated to be $24.5 \mathrm{~kJ} \mathrm{~mol}^{-1}$. Additionally, the general reaction orders with respect to S(Iv) and oxygen were found to be 0.42 and 1 , respectively.

Integrated with kinetic model of S(Iv) oxidation proposed in the present work, it could be considered that the general oxidation rate of S(Iv) in BAS solution is controlled by mass transfer of oxygen with a rapid chemical reaction. With the Hatta number determined to be about 1.4, it further confirmed the assumption of the fast-reaction regime. According to the kinetic parameters of general oxidation, it indicated that the intrinsic reaction was 0.42 order dependence on S(Iv) and firstorder dependence on oxygen, respectively. In order to fully understand the intrinsic reaction kinetics, further study on the intrinsic reaction of S(Iv) oxidation relevant to BAS rich solution is quite indispensable since little data in published literature can be referred. In addition, in terms of BAS regenerative wet FGD process, it is a key step to fully hinder the S(Iv) oxidation. Thus the oxidation inhibition of S(Iv) by screening desired inhibitors need more investigations in future work.

\section{Conflicts of interest}

The authors declare no competing financial interest.

\section{Nomenclature}

a The interfacial area per unit volume of liquid, $\mathrm{m}^{2} \mathrm{~m}^{-3}$ $C_{\mathrm{O}_{2}} \quad$ Concentration of oxygen dissolved in solution, $\mathrm{mol} \mathrm{L}^{-1}$ $C_{\mathrm{O}_{2}} \mathrm{i} \quad$ Equilibrium concentration of oxygen at the interface, $\mathrm{mol} \mathrm{L}^{-1}$

$C_{\mathrm{S}(\mathrm{vv})} \quad$ Concentration of total sulfite, $\mathrm{mol} \mathrm{L}^{-1}$

$C_{\mathrm{SO}_{4}}{ }^{2-}$ Concentration of total sulfate, $\mathrm{mol} \mathrm{L}^{-1}$

$d_{V S} \quad$ Volume-surface mean bubble diameter, $m$

$D_{\mathrm{O}_{2}} \quad$ Diffusion coefficient of oxygen in the solution, $\mathrm{m}^{2} \mathrm{~s}^{-1}$

$D_{\mathrm{R}} \quad$ Diameter of bubbling column, $m$ 
Enhanced factor of oxygen diffusion from gas into the solution

$E_{\text {a }}$

$g$

H

$k$

$k_{0}$

$k_{\mathrm{L}}$

$m$

$n$

$P_{\mathrm{O}_{2}}$

$Q$

$R$

$r$

$r_{\mathrm{A}}$

$r_{\mathrm{B}}$

$T$

$t$

$u_{\mathrm{G}}$

\section{Greek symbols}

$\begin{array}{ll}\varepsilon_{\mathrm{G}} & \text { Gas holdup } \\ \rho_{\mathrm{L}} & \text { Is density of solution, } \mathrm{kg} \mathrm{m}^{-3} \\ \mu_{\mathrm{L}} & \text { Viscosity of solution, pa s } \\ \sigma_{\mathrm{L}} & \text { Surface tension of solution, } \mathrm{N} \mathrm{m}^{-1}\end{array}$

\section{References}

1 J. Kaminski, Appl. Energy, 2003, 75, 165-172.

2 P. Córdoba, Fuel, 2015, 144, 274-286.

3 A. Lancia, D. Musmarra, F. Pepe, et al., Chem. Eng. J., 1997, 66, 123-129.

4 J. Barwasser and W. Thumn, US Pat., 2311 202, 1943.

5 R. H. Gao, Sichuan Chem. Ind., 1996, 2, 16-17.

6 M. Chen, X. H. Deng and F. Q. He, Energy Fuels, 2016, 30, 1183-1191.

7 M. Chen, X. H. Deng and F. Q. He, Energy Fuels, 2016, 30, 8469-8478.

8 G. Wen and X. L. Yu, J. Inn. Mong. Univ. Sci. Technol., 2011, 30, 356-358.

9 A. Lancia, D. Musmarra, M. Prisciandaro, et al., Chem. Eng. Sci., 1999, 54, 3019-3026.

10 A. Lancia, D. Musmarra and F. Pepe, Chem. Eng. Sci., 1996, 51, 3889-3896.
11 Z. G. Shen, S. P. Guo, W. Z. Kang, et al., Ind. Eng. Chem. Res., 2012, 51, 4192-4198.

12 T. Gürkan, A. Nufal and I. Eroğlu, Chem. Eng. Sci., 1992, 47, 3801-3808.

13 R. D. Srivastava, A. F. McMillan and I. J. Harris, Can. J. Chem. Eng., 1968, 46, 181-184.

14 H. L. J. Bäckström, J. Am. Chem. Soc., 1927, 49, 1460-1472.

15 D. Karatza, M. Prisciandaro, A. Lancia, et al., Chem. Eng. J., 2008, 145, 285-289.

16 D. Karatza, M. Prisciandaro, A. Lancia, et al., Chem. Eng. Sci., 2005, 60, 1497-1502.

17 A. A. Shaikh and S. M. J. Zaidi, React. Kinet. Catal. Lett., 1998, 64, 343-349.

18 Y. Jia, Q. Zhong, X. Y. Fan, et al., Chem. Eng. J., 2010, 164, 132-138.

19 Q. W. Li, L. D. Wang, Y. Zhao, et al., Environ. Sci. Technol., 2014, 48, 4145-4152.

20 L. D. Wang, J. Wang, P. Y. Xu, et al., Appl. Catal., A, 2015, 508, 52-60.

21 H. S. Fogler, Elements of Chemical Reaction Engineering, Prentice Hall International Series in the Physical and Chemical Engineering Science, New Jersey, 3rd edn, 2005, pp. 177-205.

22 K. Akita and F. Yoshida, Ind. Eng. Chem. Process Des. Dev., 1974, 13, 84-91.

23 E. Sada, H. Kumazawa, C. Lee, et al., Ind. Eng. Chem. Process Des. Dev., 1985, 24, 255-261.

24 E. Narita, F. Lawso and K. N. Han, Hydrometallurgy, 1983, 10, 21-37.

25 S. Bengtsson and J. Bjerle, Chem. Eng. Sci., 1975, 30, 14291435.

26 J. H. Zhou, W. Li and W. D. Xiao, Chem. Eng. Sci., 2000, 55, 5637-5641.

27 V. Linek and V. Vacek, Chem. Eng. Sci., 1981, 36, 1747-1768.

28 K. Neelakantan and J. K. Gehlawat, Ind. Eng. Chem. Fundam., 1980, 19, 36-39.

29 L. D. Wang and Y. Zhao, Chem. Eng. J., 2008, 136, 221-226.

30 N. Ahmad, İ. Eroğlu and T. Gürkan, Can. J. Chem. Eng., 1987, 65, 50-55.

31 K. Akita and F. Yoshida, Ind. Eng. Chem. Process Des. Dev., 1974, 13, 84-91.

32 M. K. Mondal, Fluid Phase Equilib., 2007, 253, 98-107.

33 E. Sada, H. Kumazawa, C. Lee, et al., Ind. Eng. Chem. Process Des. Dev., 1985, 24, 255-261. 